\title{
Puzzling Technique for Fixation of Cranioplasty Flaps
}

\author{
OMAR Y. ABDALLA, M.D. and AHMED S. FIKI, M.D. \\ The Department of Neurosurgery, Faculty of Medicine, Cairo University, Egypt
}

\begin{abstract}
Background: Cranioplasty, defined as the surgical repair of a defect in the cranium, has undergone many revolutions over time to improve patient prognosis. Cranioplasty offers cosmetic and protective benefits for patients with cranial defects.
\end{abstract}

Aim of Study: A new method for the fixation of polymethyl methacrylate (PMMA) cranioplasty flap is described, and the results of the technique were reported.

Patients and Methods: Eighteen patients with cranial defects are included in the study. Patients were followed-up by clinical examination and periodic radiographic studies for a minimum of 6 months (range 6 to 12 months). Cosmetic appearance and solid fixation of the cranioplasty flap were evaluated.

Results: Cosmetically good solid cranioplasty flaps occurred in all patients. There was no occurrence of infection or implant extrusion in any of the patients.

Conclusion: This technique appears to be a simple, safe, economic and efficient method for PMMA cranioplasty flap fixation in reconstruction of significant cranial defects.

Key Words: Cranioplasty - Poly-methyl methacrylate - Fixation-Cosmetic.

\section{Introduction}

CRANIOPLASTY is the surgical repair of cranial defects with protective and cosmetic benefits. Cranial defects usually occur following excision of tumours invading the cranium and after decompressive craniectomies. Enhancement of cerebral blood flow disturbances, electroencephalograghic irregularities and reduced occurrence of epilepsy are reported benefits of cranioplasty [1].

Whereas autologous bone grafting has cosmetic and cost advantages, donor site complications, bone resorption and decreased malleability and strength are major drawbacks [2]. Even with the use of alternative synthetic materials in cranioplasty

Correspondence to: Dr. Omar Y. Abdalla, The Department of Neurosurgery, Faculty of Medicine, Cairo University, Egypt procedures, a high complication rate was reported in several studies such as infections and sunken bone flaps $[\mathbf{3 , 4}]$.

In this study we describe a novel technique for fixation of poly-methyl methacrylate (PMMA) cranioplasty flap and the results of this technique is reported.

\section{Material and Methods}

Patients with cranial defects due to tumour invasion of the cranium, post-traumatic decompressive craniectomies and post-craniotomy osteomyelitis of the bone flap are included in the study. Patients were operated in the Neurosurgical Department of Cairo University in the period between November 2015 to December 2017.

Abstracted data included sex, age at time of cranioplasty, medical comorbidities (hypertension, diabetes), indications for craniectomy (tumour invasion, trauma, infection), time between craniectomy and cranioplasty.

Perioperative and postoperative complications were recorded. Patients were classified as having no complications, any complications, and complications requiring reoperation. All patients were followed up by clinical examination and periodic radiographic studies for a minimum of 6 months (range 6 to 12 months). Cosmetic appearance and solid fixation of the cranioplasty flap were evaluated. Two types of PMMA were randomly used in this study, DePuy high viscosity antibiotic impregnated PMMA (used in 9 patients) and Cimex high viscosity antibiotic impregnated PMMA (used in 9 patients).

\section{Surgical technique:}

After clear bone borders is obtained and watertight closure of any dural openings or tears, a series of notches are burred in the margin of the surround- 
ing cranium, preserving the inner table (Fig. 1). The notches are fashioned in a way to be slightly wider at the level of the diploe by manual rotation of the burr used in a angulated clockwise manner when the level of the diploe is reached. This notch shape is essential for fixation of the cranioplasty flap and to prevent flap extrusion being supported by the part of the outer table left above the drilled diploe. PMMA flap is fashioned and applied to the cranial defect preserving the normal cranial contour. Overflow of PMMA into the notches ensures solid fixation with the surrounding cranium (Fig. 2). No mesh, miniplates, wires or sutures are required.

\section{Results}

Eighteen patients with different pathologies were operated upon with the described technique. The study included 11 males $(61.1 \%)$ and 7 females (38.9\%), with a mean age of 40.2 years (range 2355 years old).

Indications for cranioplasty was pathological invasion of the bone flap in 6 patients, deep wound infection and osteomyelitis of the bone flap in 8 patients undergoing different craniotomy procedures and post-traumatic decompressive craniectomies in 4 patients. Hypertension was reported in 3 patients and diabetes in 2 patients. The site of cranial defect was fronto-temporal in 9 patients, fronto-tempro-parietal in 5 patients, parietal in 4 patients. The size of the cranial defect ranged from 5 to $13 \mathrm{~cm}$ in its maximum length with a mean value of $8.9 \mathrm{~cm}$.

The mean duration between decompressive craniectomy and cranioplasty was 47.9 days and 252.3 days between removal of infected bone flap and cranioplasty. In all cases of tumour invasion of the bone flap, cranioplasty was done in the same setting of tumour excision.

All patients were followed-up by clinical examination and periodic radiographic studies to detect early and late complications (Fig. 3). Followup period ranged for a minimum of 6 months postoperative up to 12 months with a mean follow up period of 8.5 months.

Cosmetically good solid cranioplasty flaps occurred in all patients. No complications were reported in 13 patients (72.2\%). Reactional sterile subgaleal collection was observed in 5 patients $(27.8 \%)$ with spontaneous resolution. There was no occurrence of infection or implant displacement in any of the patients in the follow-up period. No reoperation was reported.

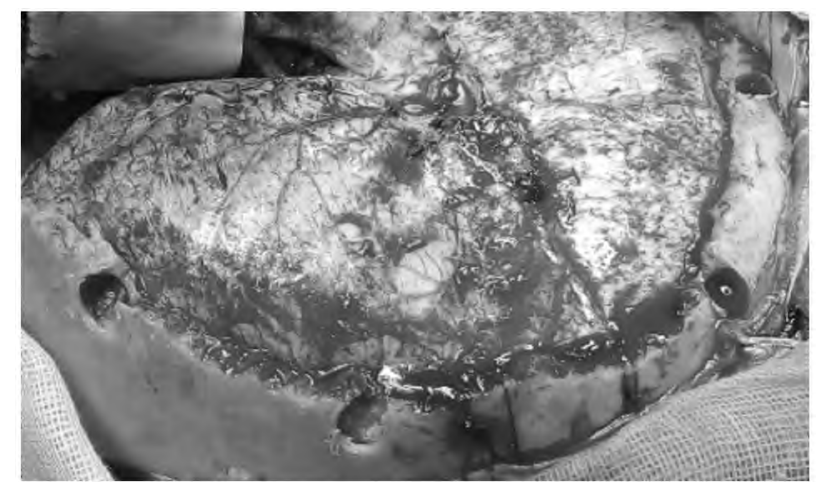

Fig. (1): Notches burred in the margin of the surrounding cranium, with preservation of the inner table. The notches are fashioned to be slightly wider at the level of the diploe.

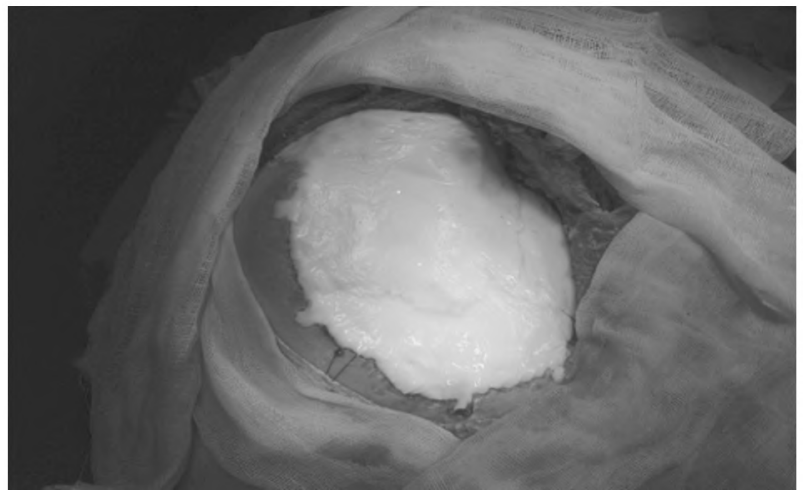

Fig. (2): Poly-methyl methacrylate flap is fashioned and applied. Overflow of poly-methyl methacrylate into the notches ensures solid fixation with the surrounding cranium.

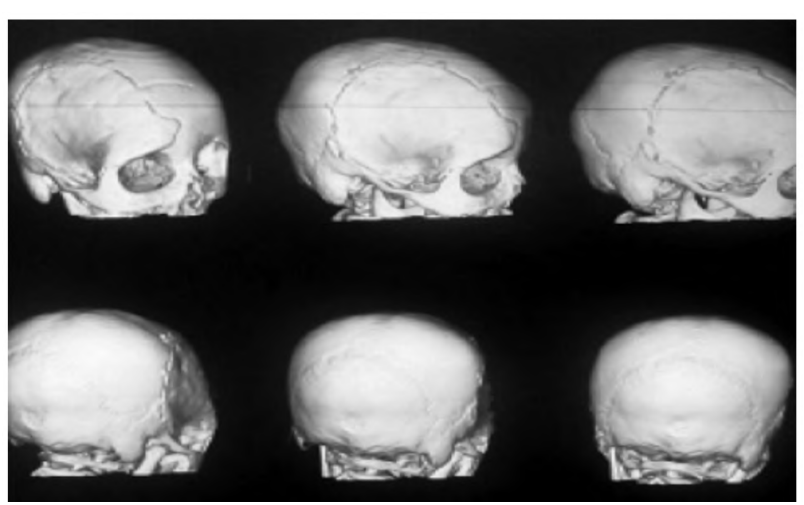

Fig. (3): Computed tomography with 3D reconstruction 6 months after surgery showing solid fixation of the poly-methyl methacrylate flap with the surrounding cranium.

\section{Discussion}

Cranioplasty has been suggested by several studies to improve physiological and clinical neurological recovery in patients with cranial defects $[5,6,7]$. No particular techniques or materials have been shown to be superior to others [3]. 
PMMA was the material used for cranioplasty in the study, which is the most commonly used cranioplasty material [8]. PMMA is a polymerized acrylic acid ester with bone-like strength and has been shown to have greater resistance and compression to stress than hydroxyapatite [9].

Research has shown acrylic to attach to the dura mater with no underlying tissue reaction [8] By time, acrylic became a more favourable cranioplasty material due to its characteristics being radiolucent, strong, heat resistant and inert [10].

However, a significant risk of infection, extrusion and decomposition was reported with PMMA $[11,12]$. Mixing with a monomer is essential to trigger an exothermic reaction to make PMMA a malleable paste, which can result in heat injuries. PMMA decomposition can result in reduced longterm protection and can even lead to infections and inflammatory reactions $[\mathbf{1 2 , 1 3 ]}$

Our surgical technique was meticulous regarding haemostasis and watertight dural closure with subgalial drains in all patients to prevent the potential impairment of the PMMA structural integrity when exposed to blood and CSF. We stayed strict with the contraindications of cranioplasty and excluded the presence of infection, hydrocephalus, and brain swelling at the time of cranioplasty.

Our series showed a complication rate of $27.8 \%$. Five out of 18 patients developed sterile reactional subgaleal collection which resolved spontaneously in all patients. None of those patients who had complications required reoperation. Our complication rate is comparable to the results obtained by Basheer et al., [3]. The authors reported a complication rate of $22.8 \%$, with $14 \%$ undergoing reoperation, in 114 patients undergoing craniopasty following decompressive craniectomy. A higher rate of complications were observed in patients who underwent cranioplasty after 24 weeks of the initial surgery, indicating that it should be performed as soon as the patient is ready for surgery. In our study the mean time between decompressive craniectomy and cranioplasty was less than 24 weeks (47.9 days).

Our complication rate was less compared to other reported studies as in Gooch et al., [4] who had complication rate of $33 \%$ and reoperation rate of $26 \%$ in a 62 patients study. They stated that the existence of a bifrontal cranial defect, which was not present in our study cases, was the only statistically correlated factor with the need for reoperation.
There was no evidence of infection in any of the patients included in the study. This result is contradictory to the known high PMMA infection rates as compared with various cranioplasty materials [14] . This difference may be due to the small number of population in the study and using PMMA alone without adjuvant miniplates, wires or sutures.

\section{Conclusion:}

This technique appears to be a simple, safe, economic and efficient method for PMMA cranioplasty flap fixation in reconstruction of significant cranial defects.

\section{References}

1- AYDIN S., KUCUKYURUK B., ABUZAYED B., AYDIN S. and SANUS G.Z.: Cranioplasty: Review of materials and techniques. J. Neurosci. Rural Pract, 2: 162-167, 2011.

2- GOLDSTEIN J.A., PALIGA J.T. and BARTLETT S.P.: Cranioplasty: Indications and advances. Curr. Opin. Otolaryngol. Head Neck Surg., 21: 400-409, 2013.

3- BASHEER N., GUPTA D., MAHAPATRA A.K. and GURJAR H.: Cranioplasty following decompressive craniectomy in traumatic brain injury: Experience at levelI apex trauma centre. Indian J. Neurotrauma, 7 (2): 139144,2010

4- GOOCH M.R., GIN G.E., KENNING T.J. and GERMAN J.W.: Complications of cranioplasty following decompressive craniectomy: Analysis of 62 cases. Neurosurg Focus, 26 (6): 9, 2009.

5- KUO J.R., WANG C.C., CHIO C.C. and CHENG T.J.: Neurological improvement after cranioplasty-analysis by transcranial Doppler ultrasonography. J. Clin. Neurosci, 11: 486-9, 2004.

6- SEGAL D.H, OPPENHEIM J.S. and MUROVIC J.A.: Neurological recovery after cranioplasty. Neurosurgery, 34: 729-31, 1994.

7- SUZUKI N., SUZUKI S. and IWABUCHI T.: Neurological improvement after cranioplasty. Analysis by dynamic CT scan. Acta. Neurochir. (Wien), 122: 49-53, 1993.

8- DROSOS G.I., BABOURDA E., MAGNISSALIS E.A., GIATROMANOLAKI A., KAZAKOS K. and VERETTAS D.A.: Mechanical characterization of bone graft substitute ceramic cements. Injury, 43 (3): 266-71, 2012.

9- MARCHAC D. and GREENSMITH A.: Long-term experience with methylmethacrylate cranioplasty in craniofacial surgery. J. Plast. Reconstr. Aesthet. Surg., 61: 744-753, 2008.

10- HENRY H.M., GUERRERO C. and MOODY R.A.: Cerebrospinal fluid fistula from fractured acrylic cranioplasty plate. Case report. J. Neurosurg., 45: 227-228, 1976.

11-CHIARINI L., FIGURELLI S., POLLASTRI G., TORCIA E., FERRARI F., ALBANESE M., et al.: Cranioplasty using acrylic material: A new technical procedure. J. Craniomaxillofac. Surg., 32: 5-9, 2004. 
12- MATSUNO A., TANAKA H., IWAMURO H., TAKANASHI S., MIYAWAKI S., NAKASHIMA M., et al: Analysis of the factors influencing bone graft infection after delayed cranioplasty. Acta. Neurochir. (Wien), 148: 535-540, 2006

13- BLUM K.S., SCHNEIDER S.J. and ROSENTHAL A.D.:
Methyl methacrylate cranioplasty in children: Long-term results. Pediatr. Neurosurg., 26: 33-35, 1997.

14- SHAH A.M., JUNG H. and SKIRBOLL S.: Materials used in cranioplasty: A history and analysis. Neurosurg. Focus, 36 (4): 19, 2014.

\section{التقنية المحيرة لتثبيت رقعة القحف التجميلية}

خفع ترقيع القحف، الذى يُعرّف بأنه الإصلاح الجراحى الثغرات فى الجمجمة، للعديد من الثوات بمرو الوقت لتحسين نتائج علاج المرضى.

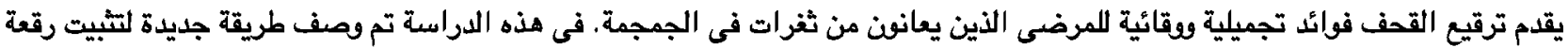

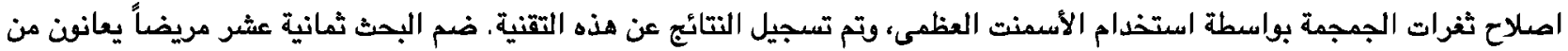

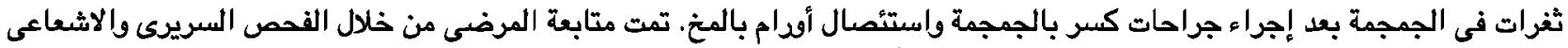

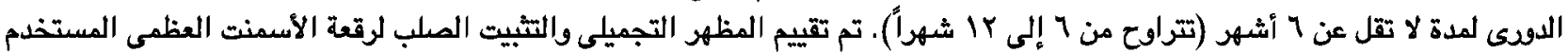

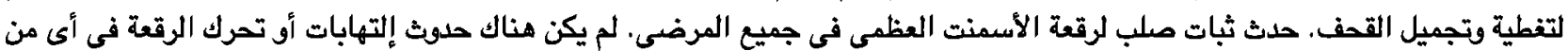

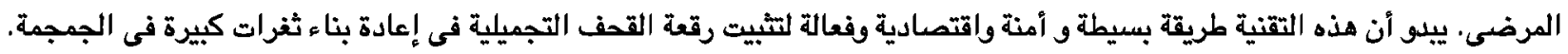

